\title{
Left ventricular efficiency after ligation of patent ductus arteriosus for premature infants
}

\author{
Hazumu Nagata, MD, ${ }^{\mathrm{a}}$ Kenji Ihara, $\mathrm{MD}, \mathrm{PhD},{ }^{\mathrm{a}}$ Kenichiro Yamamura, $\mathrm{MD},{ }^{\mathrm{a}}$ Yoshihisa Tanoue, MD, PhD, \\ Yuichi Shiokawa, MD, PhD, ${ }^{\mathrm{b}}$ Ryuji Tominaga, $\mathrm{MD}, \mathrm{PhD},{ }^{\mathrm{b}}$ and Toshiro Hara, MD, $\mathrm{PhD}^{\mathrm{a}}$
}

Objective: The purpose of this study was to evaluate the hemodynamic changes in left ventricular function before and after patent ductus arteriosus ligation in premature infants with regard to the energetic efficiency of left ventricular pumping.

\begin{abstract}
Methods: Thirty-five premature infants who underwent patent ductus arteriosus ligation were enrolled in this study. Left ventricular efficiency was evaluated at 4 points: within 24 hours before patent ductus arteriosus ligation, within 24 hours after patent ductus arteriosus ligation, between postoperative days 2 and 4 , and on postoperative day 7. The indices of contractility (end-systolic elastance) and afterload (effective arterial elastance) were approximated on the basis of the systemic blood pressure and systolic or diastolic left ventricular volume. The ratio of stroke work and pressure-volume area, representing the ventricular efficiency, was estimated using the following theoretic formula: the ratio of stroke work and pressure-volume area $=1 /(1+0.5$ ventriculoarterial coupling).
\end{abstract}

Results: Left ventricular efficiency was transiently deteriorated within 24 hours after patent ductus arteriosus ligation because of the marked increase of the afterload and the slight increase of contraction, and then recovered to preoperation levels by 2 to 4 days after patent ductus arteriosus ligation.

Conclusions: Analysis of indices representing the afterload, contractility, and energetic efficiency of the left ventricle may provide practical information for the management of premature infants during the postoperative period after patent ductus arteriosus ligation. (J Thorac Cardiovasc Surg 2013;146:1353-8)

Patent ductus arteriosus (PDA) is one of the most critical problems of the respiratory and circulatory system that can occur during the first few weeks after birth in premature infants. ${ }^{1}$ The occurrence of PDA in premature infants increases with a lower gestational age and lower birth weight. In the EPICure cohort, the occurrence of PDA was approximately $65 \%$ for infants who were born at less than 28 weeks of gestational age and approximately $80 \%$ for infants with a birth weight less than $800 \mathrm{~g} .^{2,3}$ The first-line treatment or prophylaxis for PDA is administration of indomethacin, and the second-line treatment is surgical ligation. The surgical procedure has been safely carried out by pediatric cardiothoracic surgeons; nevertheless, the postoperative intensive management is sometimes complicated because the pulmonary vascular compliance, contraction power of the cardiac muscle, and renal function are physiologically changing during the few weeks after birth. ${ }^{4}$

\footnotetext{
From the Departments of Pediatrics ${ }^{\mathrm{a}}$ and Cardiovascular Surgery, ${ }^{\mathrm{b}}$ Graduate School of Medical Sciences, Kyushu University, Fukuoka, Japan.

Disclosures: Authors have nothing to disclose with regard to commercial support.

Received for publication Nov 6, 2012; revisions received Jan 22, 2013; accepted for publication Feb 12, 2013; available ahead of print March 8, 2013.

Address for reprints: Hazumu Nagata, MD, Department of Pediatrics, Graduate

School of Medical Sciences, Kyushu University, 3-1-1 Maidashi, Higashi-ku,

Fukuoka 812-8582, Japan (E-mail: dadan@ @ediatr.med.kyushu-u.ac.jp).

$0022-5223 / \$ 36.00$

Copyright (C) 2013 by The American Association for Thoracic Surgery

http://dx.doi.org/10.1016/j.jtcvs.2013.02.019
}

For the evaluation of the hemodynamic change before and after PDA ligation, previous reports investigated the left ventricular (LV) function by echocardiogram using the indices of ejection fraction (EF), shortening fraction, mean velocity of circumferential fiber shortening, endsystolic wall stress, or systemic vascular resistance, ${ }^{5-8}$ or those by tissue Doppler imaging. ${ }^{9}$ These reports demonstrated that the increase of afterload after PDA ligation influenced LV function..$^{5-7}$ However, these reports investigated only hemodynamic changes within 24 hours of PDA ligation, and dynamic changes in the LV efficiency after PDA ligation have not been sufficiently studied. The other study using an animal model showed that PDA ligation for premature baboon neonates increased the afterload and decreased LV function as evaluated by the index of shortening fraction. ${ }^{10}$ As a new evaluation method of hemodynamics, the concept of energy efficiency has been recently applied for patients who have undergone cardiac surgery. The indices of end-systolic elastance (Ees), effective arterial elastance (Ea), and ventriculoarterial coupling (Ea/Ees) were simply calculated from blood pressure and measurements by echocardiogram, and provided a useful framework for investigating ventricular performance. ${ }^{11}$ With the use of these indices, previous reports studied the ventricular efficiency before and after aortic valve replacement ${ }^{12}$ and mitral valve surgery,${ }^{13}$ or for congenital heart disease. ${ }^{14-16}$ The current study evaluated the hemodynamic changes in LV function before and after 


\section{Abbreviations and Acronyms \\ $\mathrm{Ea}=$ effective arterial elastance \\ Ees = end-systolic elastance \\ $\mathrm{Ea} / \mathrm{Ees}=$ ventriculoarterial coupling \\ $\mathrm{EF} \quad=$ ejection fraction \\ $\mathrm{LV} \quad=$ left ventricular \\ LVEDV = left ventricular end-diastolic volume \\ LVEDVI = left ventricular end-diastolic volume index \\ LVESV = left ventricular end-systolic volume \\ LVESVI = left ventricular end-systolic volume index \\ PDA $=$ patent ductus arteriosus \\ POD $=$ postoperative day \\ $\mathrm{SD}=$ standard deviation \\ SW/ = ratio of stroke work and pressure- \\ PVA volume area}

PDA ligation in premature infants with regard to the energetic efficiency of LV pumping.

\section{MATERIALS AND METHODS \\ Patient Information}

A total of 847 premature infants (gestational age $<36$ weeks) were admitted to Kyushu University Hospital from January 2003 to December 2010. The cases accompanied with congenital heart diseases and chromosomal disorders, or in poor clinical condition, such as those with severe respiratory syndrome, bacterial sepsis, or necrotic enterocolitis, were excluded from this study. All of the premature infants born at less than 25 weeks of gestational age without an apparently severe critical condition were routinely administered prophylactic indomethacin 3 times after birth: $0.1 \mathrm{mg} / \mathrm{kg} / 6$ hours at 12 to 15 hours after birth, $0.1 \mathrm{mg} / \mathrm{kg} / 6 \mathrm{~h} 24$ hours after the first administration, and $0.1 \mathrm{mg} / \mathrm{kg} / 6$ hours 24 hours after the second administration. The infants born at 25 weeks and more than 25 weeks of gestational age were treated with indomethacin only when clinical symptoms were observed, such as tachypnea, tachycardia, and a reduction of urine output due to PDA. The dose of indomethacin was $0.1 \mathrm{mg} / \mathrm{kg} / 6$ hours; if the PDA did not close, the same dose was administered a second and third time 24 hours after the first and second treatments, respectively. If the indomethacin treatment did not effectively close the PDA and symptomatic heart failure persisted because of the presence of PDA, surgical PDA ligation was performed. Informed consent for the surgery was obtained from the parents of all patients. All retrospective data used in this study were obtained by means of charts and electronic database reviews.

\section{Surgical Technique}

PDA ligation was performed using standard methods. Anesthesia was conducted in intubated infants by a standard technique, with intravenous infusions of fentanyl and the muscle relaxant pancuronium. The patients were placed in a right lateral position, and a standard left posterolateral thoracotomy was performed through the third intercostal space. A single ligation of the PDA was performed with a silk suture.

\section{Analysis of Cardiovascular Function by Echocardiogram}

The LV efficiency before and after PDA ligation was evaluated by transthoracic echocardiogram at 4 points: within 24 hours before PDA ligation, within 24 hours after PDA ligation, between postoperative days (PODs) 2 and 4, and on POD 7. The LV end-diastolic volume (LVEDV) and LV end-systolic volume (LVESV) were calculated by the Teichholz M-mode method based on the data about the LV end-diastolic dimension and the end-systolic dimension obtained from the echocardiogram. ${ }^{17}$ The LV end-diastolic volume index (LVEDVI), LV end-systolic volume index (LVESVI), and EF were calculated as follows: LVEDVI (mL/ $\left.\mathrm{m}^{2}\right)=$ LVEDV/body surface area, LVESVI $\left(\mathrm{mL} / \mathrm{m}^{2}\right)=$ LVESV/body surface area, $\mathrm{EF}(\%)=(1-\mathrm{LVESV} / \mathrm{LVEDV}) \times 100$. The arterial blood pressure was measured by the Korotkoff technique using the manchette method. The indices of contractility (Ees) and afterload (Ea) were calculated on the basis of the systemic blood pressure and cardiac volume data using the approximation method, as described previously. ${ }^{18}$ The approximation of the Ees and Ea was performed as follows: Ees = mean blood pressure /minimal LV volume; Ea = maximal LV pressure/(maximal LV volume - minimal LV volume). The mean blood pressure was calculated as follows: mean blood pressure $=$ (systolic blood pressure + diastolic blood pressure $\times 2$ )/3. The maximal LV pressure was approximated by the systolic blood pressure. The maximal LV volume was defined as being equal to the LVEDV, and the minimal LV volume was defined as being equal to the LVESV. The Ea/Ees indicates the ventriculoarterial coupling between the left ventricle and the arterial system. ${ }^{11}$ The ratio of stroke work and pressure-volume area (SW/PVA) represents the LV efficiency, which was estimated using the theoretic formula SW/ $\mathrm{PVA}=1 /(1+0.5 \mathrm{Ea} / \mathrm{Ees}){ }^{19}$

\section{Statistical Analysis}

The values are presented as the mean values \pm standard deviation (SD). An analysis of variance with repeated measures on 1 factor was used for the variables measured at the 4 points (within 24 hours before PDA ligation, within 24 hours after PDA ligation, between PODs 2 and 4, and on POD 7). The Student Newman-Keuls test was used as a post hoc test.

\section{RESULTS}

\section{Clinical Manifestations}

Among the 847 premature infants, 98 were treated with indomethacin for the closure of or prophylaxis for PDA, and 63 of these PDA cases were closed by $5.8 \pm 4.1$ days of age. There were 35 patients with persistent PDA even after indomethacin treatment, and surgical PDA ligation was performed in all of these infants. The mean \pm SD gestational age of these infants was $27.2 \pm 4.4$ weeks, and their birth weight was $934 \pm 499 \mathrm{~g}$. The narrowest PDA diameter was $2.43 \pm 1.08 \mathrm{~mm}$. The bloodflow speed in the PDA was $2.16 \pm 0.80 \mathrm{~m} / \mathrm{sec}$. Surgical PDA ligation was performed at $23.5 \pm 11.6$ days of age. The body weight of the infants at PDA ligation was $978 \pm 504 \mathrm{~g}$. The length of the operation was $37.2 \pm 9.3$ minutes. No critical complications developed in any of the patients during the operation (Table 1). Eighteen of 35 patients were treated with dopamine or dobutamine before surgery to assist cardiac function. After surgery, all patients, including these 18, were given a dopamine or dobutamine infusion at a dose of 3 to 5 $\mu \mathrm{g} / \mathrm{kg} / \mathrm{min}$ for at least 24 hours, but vasodilating agents (eg, phosphodiesterase 3 inhibitors) were not used. Eighteen patients were managed under mechanical ventilation before the surgery, and all of the patients were controlled under mechanical ventilation for at least 3 days after the surgery. Detailed data on circulatory and respiratory supports for the patients 
TABLE 1. Patient characteristics

\begin{tabular}{|c|c|c|c|c|c|}
\hline & \multirow[b]{2}{*}{ Total no. $N=847$} & \multicolumn{3}{|c|}{ Patients with PDA } & \multirow[b]{2}{*}{$\begin{array}{c}\text { Control patients } \\
\quad \mathbf{N}=\mathbf{2 7} \\
\end{array}$} \\
\hline & & Total $\mathbf{N}=\mathbf{9 8}$ & $\begin{array}{l}\text { Closed by indomethacin } \\
\qquad N=63\end{array}$ & $\begin{array}{c}\text { Closed by ligation } \\
\quad \mathrm{N}=\mathbf{3 5} \\
\end{array}$ & \\
\hline Male/female & $461 / 386$ & $51 / 47$ & $32 / 31$ & $19 / 16$ & $14 / 13$ \\
\hline Gestational age (wk) & $31.4 \pm 3.2$ & $26.9 \pm 4.2$ & $26.8 \pm 4.3$ & $27.2 \pm 4.4$ & $27.3 \pm 4.6$ \\
\hline Birth weight (g) & $1588 \pm 518$ & $938 \pm 441$ & $940 \pm 423$ & $934 \pm 499$ & $980 \pm 503$ \\
\hline RDS $(\%)$ & $197(23.2)$ & $57(59.1)$ & $46(74.1)$ & $12(36.3)$ & $14(51.8)$ \\
\hline CLD $(\%)$ & $89(10.5)$ & $38(38.7)$ & $27(43.1)$ & $11(33.3)$ & $10(37.0)$ \\
\hline $\mathrm{ICH}(\%)$ & $6(0.69)$ & $6(7.1)$ & $6(10.3)$ & $1(3)$ & $2(7.4)$ \\
\hline NEC $(\%)$ & $4(0.48)$ & $2(2.0)$ & $2(3.4)$ & $0(0)$ & $1(3.7)$ \\
\hline $\mathrm{ROP}(\%)$ & $13(15.7)$ & $40(40.8)$ & $27(43.1)$ & $13(39.3)$ & $13(48.1)$ \\
\hline Death $(\%)$ & $5(5.4)$ & $1(1.0)$ & $1(1.7)$ & $0(0)$ & $0(0)$ \\
\hline \multicolumn{6}{|l|}{ PDA closure } \\
\hline Age (d) & & & $5.8 \pm 4.1$ & $23.5 \pm 11.6$ & \\
\hline Body weight (g) & & & $941 \pm 445$ & $978 \pm 504$ & \\
\hline Narrowest PDA diameter $(\mathrm{mm})$ & & & & $2.43 \pm 1.08$ & \\
\hline Blood-flow speed in PDA $(\mathrm{m} / \mathrm{s})$ & & & & $2.16 \pm 0.80$ & \\
\hline
\end{tabular}

Data are shown as the mean $\pm \mathrm{SD}$. $P D A$, Patent ductus arteriosus; $R D S$, respiratory distress syndrome; $C L D$, chronic lung disease; $I C H$, intracerebral hemorrhage; $N E C$, necrotizing enterocolitis; $R O P$, retinopathy of prematurity.

before and after PDA ligation are shown in Table 2. No major complications occurred in any of the patients after surgery, such as pneumothorax, chylothorax, hemothorax, hypotension, vocal cord paralysis, or infection. Clinical data, such as blood pressure, heart rate, oxygen saturation, urine output, and blood $\mathrm{pH}$, are shown in Table 3. Soon after the operation, the blood pressures were remarkably increased, whereas other parameters (eg, heart rate or oxygen saturation) were not significantly changed.

Twenty-seven premature infants, whose ductus arteriosus was closed spontaneously, were also studied and compared with the 35 infants in whom surgical PDA ligation was performed; they are shown as control patients in Table 1. There were no significant differences in the clinical characteristics between them.

\section{Hemodynamics}

The points evaluated by echocardiogram were as follows: within 24 hours before PDA ligation (mean $\pm \mathrm{SD}, 8.4 \pm 5.8$ hours; range, 3-21 hours), within 24 hours after PDA ligation (mean $\pm \mathrm{SD}, 5.5 \pm 4.0$ hours; range, $1-18$ hours), between PODs 2 and 4 (mean \pm SD, $70.6 \pm 14.6$ hours; range, 49-92 hours), and on POD 7 (mean \pm SD, $164 \pm 2.6$ hours; range, $160-169$ hours). For the evaluation at the third point (PODs 2-4), approximately two thirds of the patients (25/35) were examined. As shown in Table 4, the LV EF decreased significantly within 24 hours after the operation (from $74.1 \% \pm 10.2 \%$ to $63.5 \% \pm 9.8 \%$, $P<.05)$, but the EF recovered to the preoperation level by PODs 2 to 4 in most patients and gradually increased until POD $7(75.6 \% \pm 6.4 \%$ and $79.5 \% \pm 7.6 \%$,

TABLE 2. Circulatory and respiratory supports before and after patent ductus arteriosus ligation

\begin{tabular}{|c|c|c|c|c|}
\hline & Within 24 h before PDA ligation & Within $24 \mathrm{~h}$ after PDA ligation & Postoperative days 2-4 & Postoperative day 7 \\
\hline \multicolumn{5}{|l|}{ Mean doses of catecholamines } \\
\hline Dopamine $(\mu \mathrm{g} / \mathrm{kg} / \mathrm{min})$ & $1.66 \pm 1.77(\mathrm{~N}=18)$ & $3.30 \pm 0.98 *(\mathrm{~N}=35)$ & $0.36 \pm 1.12 *(\mathrm{~N}=4)$ & $0.08 \pm 0.50 *(\mathrm{~N}=1)$ \\
\hline Dobutamine $(\mu \mathrm{g} / \mathrm{kg} / \mathrm{min})$ & $0.16 \pm 0.69(\mathrm{~N}=2)$ & $0.30 \pm 1.06(\mathrm{~N}=4)$ & $0.07 \pm 0.48(\mathrm{~N}=1)$ & $0.0(\mathrm{~N}=0)$ \\
\hline $\begin{array}{l}\text { Mean doses of IV fluid } \\
\text { administration }(\mathrm{mL} / \mathrm{kg} / \mathrm{h})\end{array}$ & $4.53 \pm 1.71(\mathrm{~N}=35)$ & $4.61 \pm 1.71(\mathrm{~N}=35)$ & $4.80 \pm 1.22(\mathrm{~N}=25)$ & $5.76 \pm 1.22 *(\mathrm{~N}=35$ \\
\hline Mechanical ventilation & $(\mathrm{N}=18)$ & $(\mathrm{N}=35)$ & $(\mathrm{N}=17)$ & $(\mathrm{N}=17)$ \\
\hline Mean $\mathrm{FIO}_{2}$ & $0.24 \pm 0.05$ & $0.25 \pm 0.08$ & $0.22 \pm 0.02$ & $0.22 \pm 0.03$ \\
\hline SIMV & $(\mathrm{N}=8)$ & $(\mathrm{N}=24)$ & $(\mathrm{N}=8)$ & $(\mathrm{N}=6)$ \\
\hline $\mathrm{RR}(/ \mathrm{min})$ & $35.5 \pm 9.1$ & $33.7 \pm 7.9$ & $31.2 \pm 8.7$ & $26.7 \pm 8.7^{*}$ \\
\hline PIP (mm Hg) & $20.1 \pm 3.60$ & $18.9 \pm 4.33$ & $15.5 \pm 4.65^{*}$ & $16.6 \pm 5.3$ \\
\hline PEEP $(\mathrm{mm} \mathrm{Hg})$ & $4.84 \pm 0.80$ & $4.90 \pm 0.42$ & $4.63 \pm 0.67$ & $4.60 \pm 0.69$ \\
\hline $\mathrm{HFO}$ & $(\mathrm{N}=10)$ & $(\mathrm{N}=11)$ & $(\mathrm{N}=9)$ & $(\mathrm{N}=11)$ \\
\hline MAP $(\mathrm{mm} \mathrm{Hg})$ & $10.2 \pm 0.63$ & $10.2 \pm 1.19$ & $9.80 \pm 1.39$ & $9.45 \pm 1.50$ \\
\hline $\mathrm{SV}(\mathrm{mL})$ & $10.5 \pm 1.58$ & $10.0 \pm 1.00$ & $9.50 \pm 1.71$ & $9.36 \pm 1.91$ \\
\hline
\end{tabular}

Data are presented as mean \pm SD. $N$, Number of the treated patients. $P D A$, patent ductus arteriosus; $I V$, intravenous; FiO $O_{2}$, Fractional inspired oxygen concentration; $S I M V$, synchronized intermittent mandatory ventilation; $R R$, respiratory rate; $P I P$, peak inspiratory pressure; $P E E P$, positive end-expiratory pressure; $H F O$, high-frequency oscillation; $M A P$, mean airway pressure; $S V$, stroke volume. $* P<.05$ versus before PDA ligation. 
TABLE 3. Clinical data before and after patent ductus arteriosus ligation

\begin{tabular}{|c|c|c|c|c|}
\hline & $\begin{array}{c}\text { Within } 24 \mathrm{~h} \text { before PDA } \\
\text { ligation }\end{array}$ & $\begin{array}{c}\text { Within } 24 \text { h after PDA } \\
\text { ligation }\end{array}$ & Postoperative days $2-4 \dagger$ & Postoperative day 7 \\
\hline Systolic BP (mm Hg) & $54.6 \pm 7.89$ & $59.1 \pm 11.9$ & $61.4 \pm 8.46^{*}$ & $60.7 \pm 10.5^{*}$ \\
\hline Diastolic BP (mm Hg) & $28.3 \pm 7.37$ & $36.4 \pm 7.43^{*}$ & $37.8 \pm 7.73^{*}$ & $38.0 \pm 10.3^{*}$ \\
\hline Mean BP (mm Hg) & $36.8 \pm 6.72$ & $43.2 \pm 8.38^{*}$ & $45.2 \pm 6.95^{*}$ & $45.4 \pm 10.2 *$ \\
\hline Heart rates (beats/min) & $152 \pm 8.53$ & $153 \pm 8.79$ & $148 \pm 8.75$ & $148 \pm 8.50$ \\
\hline $\mathrm{SpO}_{2}(\%)$ & $96.6 \pm 2.88$ & $96.7 \pm 2.86$ & $94.1 \pm 16.4$ & $97.4 \pm 1.71$ \\
\hline \multicolumn{5}{|l|}{ Blood gas data } \\
\hline $\mathrm{pH}$ & $7.38 \pm 0.07$ & $7.37 \pm 0.07$ & $7.40 \pm 0.05$ & $7.39 \pm 0.06$ \\
\hline $\mathrm{BE}$ & $1.95 \pm 4.28$ & $1.00 \pm 4.32$ & $3.47 \pm 3.48$ & $1.80 \pm 2.24$ \\
\hline Lactate $(\mathrm{mmol} / \mathrm{L})$ & $1.72 \pm 0.80$ & $1.68 \pm 0.91$ & $1.44 \pm 0.47$ & $0.71 \pm 1.71$ \\
\hline Urine output $(\mathrm{mL} / \mathrm{kg} / \mathrm{h})$ & $3.37 \pm 1.30$ & $4.05 \pm 2.27$ & $4.21 \pm 1.49$ & $4.45 \pm 1.46^{*}$ \\
\hline
\end{tabular}

Data are presented as the mean \pm SD. $P D A$, Patent ductus arteriosus; $B P$, blood pressure; $S p o_{2}$, Saturation of peripheral oxygen; $B E$, base excess. *P<.05 versus before PDA ligation. $\nmid$ Twenty-five of 35 patients were evaluated.

respectively). The Ea index increased significantly within 24 hours after PDA ligation (from $1.25 \pm 0.53 \mathrm{~mm} \mathrm{Hg}$ / $\mathrm{mL} / \mathrm{m}^{2}$ to $\left.2.66 \pm 0.96 \mathrm{~mm} \mathrm{Hg} / \mathrm{mL} / \mathrm{m}^{2}, P<.05\right)$ but gradually decreased after that time point (at PODs 2-4: $2.26 \pm 0.72 \mathrm{~mm} \mathrm{Hg} / \mathrm{mL} / \mathrm{m}^{2}$, at POD 7: $2.01 \pm 0.83 \mathrm{~mm}$ $\mathrm{Hg} / \mathrm{mL} / \mathrm{m}^{2}$ ). The Ees index slightly increased within 24 hours after PDA ligation, but the increase was not statistically significant (from $2.46 \pm 1.88 \mathrm{~mm} \mathrm{Hg} / \mathrm{mL} / \mathrm{m}^{2}$ to $2.92 \pm 1.95 \mathrm{~mm} \mathrm{Hg} / \mathrm{mL} / \mathrm{m}^{2}$ ), whereas the index was drastically increased at PODs 2 to $4\left(4.64 \pm 1.22 \mathrm{~mm} \mathrm{Hg} / \mathrm{mL} / \mathrm{m}^{2}\right)$ and was maintained at the same level until POD 7 $\left(4.45 \pm 2.87 \mathrm{~mm} \mathrm{Hg} / \mathrm{mL} / \mathrm{m}^{2}\right)$. The $\mathrm{SW} / \mathrm{PVA}$ ratio decreased significantly within 24 hours after PDA ligation (from $76.3 \% \pm 8.0 \%$ to $66.6 \% \pm 11.2 \%$ ), but recovered to the preoperation level by PODs 2 to 4 , and the ratio was maintained until POD $7(78.7 \% \pm 7.8 \%$ and $78.6 \% \pm 8.2 \%$, respectively). All of the hemodynamic data at POD 7 were approximately the same as those of the control patients. Because the hemodynamic change within 24 hours might be variable, we reevaluated the hemodynamic indices in all of the patients divided by the first evaluation time within 24 hours after PDA ligation. As a result, there were no significant changes in the indices among the groups (Appendix Table 1). We assessed the circulatory and respiratory findings between those under myocardial depression
$(\mathrm{Ea} / \mathrm{Ees} \geq 1.0)$ or not $(\mathrm{Ea} / \mathrm{Ees}<1.0)$ and found that conditions under circulatory and respiratory support did not have any significant differences between the groups within 24 hours after PDA ligation (Appendix Table 2).

\section{DISCUSSION}

The presence of PDA in infants may play an important role in their adaptation to the hemodynamic changes after birth. The PDA can maintain adequate arterial oxygen ten$\operatorname{sion}^{20}$ and protect the immature ventricle against afterload by maintaining low vascular resistance for a few hours after delivery in premature infants. ${ }^{10}$ However, a persistent PDA causes an inadequate blood flow balance in the pulmonary and systemic circulation, causing various clinical problems. PDA closure at an appropriate time is thus needed for premature infants. Some of them require surgical intervention, but postoperative LV hypofunction sometimes occurs after PDA ligation. ${ }^{21}$ To improve the safe management of premature infants after PDA ligation, we investigated the time course of hemodynamic changes before and after PDA ligation with regard to the energy efficiency of the left ventricle.

The energetic efficiency of the heart is defined as the ratio of stroke work $(\mathrm{SW})^{22}$ to myocardial oxygen consumption. The oxygen consumption is linearly correlated with the

TABLE 4. Hemodynamic data before and after patent ductus arteriosus ligation

\begin{tabular}{lccccc}
\hline & $\begin{array}{c}\text { Within 24 h before } \\
\text { PDA ligation }\end{array}$ & $\begin{array}{c}\text { Within 24 h after } \\
\text { PDA ligation }\end{array}$ & Postoperative days 2-4 $\dagger$ & Postoperative day 7 & Control patients \\
\hline LVEDVI $\left(\mathrm{mL} / \mathrm{m}^{2}\right)$ & $70.8 \pm 37.9$ & $49.6 \pm 30.3^{*}$ & $41.7 \pm 23.3^{*}$ & $48.0 \pm 31.1^{*}$ & $49.8 \pm 10.5^{*}$ \\
LVESVI $\left(\mathrm{mL} / \mathrm{m}^{2}\right)$ & $21.7 \pm 15.2$ & $22.2 \pm 16.3$ & $12.5 \pm 8.0^{*} \dagger$ & $14.2 \pm 10.2^{*}, \dagger$ & $14.9 \pm 7.4^{*}, \dagger$ \\
EF $(\%)$ & $74.1 \pm 10.2$ & $63.5 \pm 9.8^{*}$ & $75.6 \pm 6.4 \dagger$ & $79.5 \pm 7.6 \dagger$ & $80.1 \pm 10.0 \dagger$ \\
Ea $\left(\mathrm{mm} \mathrm{Hg} / \mathrm{mL} / \mathrm{m}^{2}\right)$ & $1.25 \pm 0.53$ & $2.66 \pm 0.96^{*}$ & $2.26 \pm 0.72^{*}$ & $2.01 \pm 0.83^{*}$ & $2.11 \pm 0.77^{*}$ \\
Ees $\left(\mathrm{mm} \mathrm{Hg} / \mathrm{mL} / \mathrm{m}^{2}\right)$ & $2.46 \pm 1.88$ & $2.92 \pm 1.95$ & $4.64 \pm 1.22^{*}, \dagger$ & $4.45 \pm 2.87^{*}, \dagger$ & $4.52 \pm 2.73^{*}, \dagger$ \\
Ea/Ees & $0.64 \pm 0.28$ & $1.10 \pm 0.57^{*}$ & $0.56 \pm 0.42 \dagger$ & $0.56 \pm 0.28 \dagger$ & $0.55 \pm 0.23 \dagger$ \\
SW/PVA $(\%)$ & $76.3 \pm 8.0$ & $66.6 \pm 11.2^{*}$ & $78.7 \pm 7.8 \dagger$ & $78.6 \pm 8.2 \dagger$ & $79.2 \pm 10.5 \dagger$ \\
\hline
\end{tabular}

Data are presented as the mean \pm SD. $P D A$, Patent ductus arteriosus; $L V E D V I$, left ventricular end-diastolic volume index; $L V E S V I$, left ventricular end-systolic volume index; $E F$, ejection fraction; Ea, effective arterial elastance; Ees, end-systolic elastance; Ea/Ees, ventriculoarterial coupling; $S W / P V A$, ratio of stroke work and pressure-volume area. $* P<.05$ versus before PDA ligation. $\dagger P<.05$ versus within 24 hours after PDA ligation. $\ddagger$ Twenty-five of the 35 patients were evaluated. 
pressure-volume area (PVA) ${ }^{23}$; thus, the energetic efficiency can be estimated from the ratio of the SW to the PVA. The Ea/Ees represents the ventriculoarterial coupling between the left ventricle and the arterial system, and indicates the balance between contractility and afterload. The energetic efficiency (SW/PVA) was simply calculated from the Ea/Ees. ${ }^{19}$ Theoretic study and clinical data for the patients with normal heart function showed that the SW of ventricular contraction was maximized when Ea/ Ees $=1$ under a constant level of myocardial oxygen consumption, ${ }^{22}$ whereas the energetic efficiency of ventricular contraction was maximized when $\mathrm{Ea} / \mathrm{Ees}=0.5 .{ }^{11}$ The present study showed that the $\mathrm{Ea} / \mathrm{Ees}$ index was more than 1.0 within 24 hours after PDA ligation, indicating that the LV efficiency was impaired soon after PDA ligation. The LV contraction (Ees) drastically improved by 2 to 4 days after PDA ligation, whereas the afterload (Ea) gradually recovered, but was still at a higher level 7 days after ligation than in the preoperation state. In contrast, the transient deterioration of the LV energy efficiency after PDA ligation was recovered within 2 to 4 days after ligation. These parameters made it possible to assess the hemodynamic changes of LV contraction, afterload, and energy efficiency separately.

In the present study, none of the 35 premature infants showed any respiratory complications or systemic hypotension after PDA ligation. If the patients have any pre- or postoperative complications that may affect their systemic hemodynamics, the present data would be helpful for determining the drug indications. For example, in cases of systemic hypotension within 24 hours after PDA ligation, inotropic agents such as dopamine or epinephrine should be used to increase LV contractility (Ees) in addition to phosphodiesterase inhibitors to decrease the afterload (Ea). Beginning 24 hours after PDA ligation, vasodilators to decrease the afterload would be the essential and firstline treatment.

\section{Study Limitations}

The findings in this study provide useful information for the critical management of the circulatory and respiratory conditions for premature infants after PDA ligation. However, there were several limitations to this study. First, the accuracy of the approximation of the Ea and Ees on the basis of echocardiography in the premature infants has not been evaluated. Thus, a comparison of data obtained from a catheter system ${ }^{24}$ and by echocardiography at each time point, if possible, would be useful in a future study. Second, we did not assess any premature infants without PDA; therefore, further study for those will be important to uncover the particular effect by existence of PDA. Third, we did not take into consideration the possible modification of the indices by anesthesia. Because the anesthetizing agents fentanyl and pancuronium could alter the LV contraction and afterload, further study to evaluate the effects of these drugs is important. In addition, we did not discuss the effect of preload because the energy efficiency of the left ventricle (Ea, Ees) is theoretically independent of the preload. Nevertheless, it was likely that preload could influence the LV contraction; thus, further comprehensive evaluation of the preload by standard methods, such as the early and atrial mitral inflow velocities, ${ }^{6}$ in combination with the energy efficiency would give us information to reveal detailed cardiovascular status before and after PDA ligation. Finally, we did not have data from a conductance catheter technique; thus, a comparison of data obtained from a catheter system and by echocardiography at each time point, if possible, would be useful in a future study.

\section{CONCLUSIONS}

We investigated the LV function in terms of the energetic efficiency before and after PDA ligation. This study showed that the LV efficiency was transiently deteriorated within 24 hours after PDA ligation because of a marked increase of the afterload and a slight increase in contractility, and then recovered to preoperation levels 2 to 4 days after PDA ligation. The consecutive evaluations of the afterload, contractility, and energetic efficiency of LV function may provide practical information for the management for premature infants during the period after PDA ligation.

The authors thank the staff at the neonatal intensive care unit of Kyushu University Hospital for support of this work.

\section{References}

1. Stoll BJ, Hansen NI, Bell EF, Shankaran S, Laptook AR, Walsh MC, et al. Neonatal outcomes of extremely preterm infants from the NICHD Neonatal Research Network. Pediatrics. 2010;126:443-56.

2. Costeloe K, Hennessy E, Gibson AT, Marlow N, Wilkinson AR. The EPICure study: outcomes to discharge from hospital for infants born at the threshold of viability. Pediatrics. 2000;106:659-71.

3. Koch J, Hensley G, Roy L, Brown S, Ramaciotti C, Rosenfeld CR. Prevalence of spontaneous closure of the ductus arteriosus in neonates at a birth weight of 1000 grams or less. Pediatrics. 2006;117:1113-21

4. Mandhan P, Brown S, Kukkady A, Samarakkody U. Surgical closure of patent ductus arteriosus in preterm low birth weight infants. Congenit Heart Dis. 2009;4:34-7.

5. Kimball TR, Ralston MA, Khoury P, Crump RG, Cho FS, Reuter JH. Effect of ligation of patent ductus arteriosus on left ventricular performance and its determinants in premature neonates. J Am Coll Cardiol. 1996;27:193-7.

6. Noori S, Friedlich P, Seri I, Wong P. Changes in myocardial function and hemodynamics after ligation of the ductus arteriosus in preterm infants. $J$ Pediatr. 2007; 150:597-602

7. McNamara PJ, Stewart L, Shivananda SP, Stephens D, Sehgal A. Patent ductus arteriosus ligation is associated with impaired left ventricular systolic performance in premature infants weighing less than $1000 \mathrm{~g}$. J Thorac Cardiovasc Surg. 2010;140:150-7.

8. Galal MO, Amin M, Hussein A, Kouatli A, Al-Ata J, Jamjoom A. Left ventricular dysfunction after closure of large patent ductus arteriosus. Asian Cardiovasc Thorac Ann. 2005;13:24-9.

9. El-Khuffash AF, Jain A, Dragulescu A, McNamara PJ, Mertens L. Acute changes in myocardial systolic function in preterm infants undergoing patent ductus arteriosus ligation: a tissue Doppler and myocardial deformation study. J Am Soc Echocardiogr. 2012;25:1058-67. 
10. Taylor AF, Morrow WR, Lally KP, Kinsella JP, Gerstmann DR, deLemos RA. Left ventricular dysfunction following ligation of the ductus arteriosus in the preterm baboon. J Surg Res. 1990;48:590-6.

11. Burkhoff D, Sagawa K. Ventricular efficiency predicted by an analytical model. Am J Physiol. 1986;250:R1021-7.

12. Tanoue Y, Maeda T, Oda S, Baba H, Oishi Y, Tokunaga S, et al. Left ventricular performance in aortic valve replacement. Interact Cardiovasc Thorac Surg. 2009;9:255-9.

13. Imasaka KI, Tomita Y, Tanoue Y, Tominaga R, Tayama E, Onitsuka H, et al. Early mitral valve surgery for chronic severe mitral regurgitation optimizes left ventricular performance and left ventricular mass regression. J Thorac Cardiovasc Surg. 2012 Jun 18 [Epub ahead of print].

14. Tanoue Y, Kado H, Maeda T, Shiokawa Y, Fusazaki N, Ishikawa S. Left ventricular performance of pulmonary atresia with intact ventricular septum after right heart bypass surgery. J Thorac Cardiovasc Surg. 2004;128:710-7.

15. Tanoue Y, Kado H, Shiokawa Y, Fusazaki N, Ishikawa S. Midterm ventricular performance after Norwood procedure with right ventricular-pulmonary artery conduit. Ann Thorac Surg. 2004;78:1965-71.

16. Tanoue Y, Sese A, Imoto Y, Joh K. Ventricular mechanics in the bidirectional Glenn procedure and total cavopulmonary connection. Ann Thorac Surg. 2003;76:562-6.

17. Teichholz LE, Kreulen T, Herman MV, Gorlin R. Problems in echocardiographic volume determinations: echocardiographic-angiographic correlations in the presence of absence of asynergy. Am J Cardiol. 1976;37:7-11.
18. Tanoue Y, Sese A, Ueno Y, Joh K, Hijii T. Bidirectional Glenn procedure improves the mechanical efficiency of a total cavopulmonary connection in high-risk Fontan candidates. Circulation. 2001;103:2176-80.

19. Nozawa T, Yasumura Y, Futaki S, Tanaka N, Uenishi M, Suga H. Efficiency of energy transfer from pressure-volume area to external mechanical work increases with contractile state and decreases with afterload in the left ventricle of the anesthetized closed-chest dog. Circulation. 1988;77:1116-24.

20. Clyman RI, Mauray F, Heymann MA, Roman C. Cardiovascular effects of patent ductus arteriosus in preterm lambs with respiratory distress. J Pediatr. 1987;111: 579-87.

21. Jhaveri N, Moon-Grady A, Clyman RI. Early surgical ligation versus a conservative approach for management of patent ductus arteriosus that fails to close after indomethacin treatment. J Pediatr. 2010;157:381-7.e381.

22. Sunagawa K, Maughan WL, Sagawa K. Optimal arterial resistance for the maximal stroke work studied in isolated canine left ventricle. Circ Res. 1985;56: 586-95.

23. Suga H, Hayashi T, Suehiro S, Hisano R, Shirahata M, Ninomiya I. Equal oxygen consumption rates of isovolumic and ejecting contractions with equal systolic pressure-volume areas in canine left ventricle. Circ Res. 1981;49: 1082-91.

24. Mori Y, Takahashi K, Nakanishi T. Complications of cardiac catheterization in adults and children with congenital heart disease in the current era. Heart Vessels. March 29, 2012 [Epub ahead of print].
APPENDIX TABLE 1. Hemodynamic data within 24 hours after patent ductus arteriosus ligation

\begin{tabular}{lcccc}
\hline & $\begin{array}{c}\text { Within 2 h } \\
(\mathbf{N}=\mathbf{2 3})\end{array}$ & $\begin{array}{c}\text { At 2-6 h } \\
(\mathbf{N}=\mathbf{4})\end{array}$ & $\begin{array}{c}\text { At 6-9 h } \\
(\mathbf{N}=\mathbf{1})\end{array}$ & $\begin{array}{c}\text { At 12-18 h } \\
(\mathbf{N}=\mathbf{7})\end{array}$ \\
\hline $\mathrm{Ea}\left(\mathrm{mm} \mathrm{Hg} / \mathrm{mL} / \mathrm{m}^{2}\right)$ & $2.44 \pm 0.97$ & $2.50 \pm 0.45$ & 2.13 & $2.10 \pm 0.64$ \\
$\mathrm{Ees}\left(\mathrm{mm} \mathrm{Hg} / \mathrm{mL} / \mathrm{m}^{2}\right)$ & $2.79 \pm 1.46$ & $2.32 \pm 1.03$ & 2.18 & $1.86 \pm 1.07$ \\
$\mathrm{Ea} / \mathrm{Ees}$ & $1.03 \pm 0.46$ & $1.12 \pm 0.29$ & 0.98 & $1.16 \pm 0.55$ \\
SW/PVA $(\%)$ & $67.6 \pm 10.0$ & $64.4 \pm 6.21$ & 67.2 & $64.8 \pm 10.8$ \\
\hline
\end{tabular}

Data are presented as the mean \pm SD. Ea, Effective arterial elastance; Ees, endsystolic elastance; Ea/Ees, ventriculoarterial coupling; SW/PVA, ratio of stroke work and pressure-volume area.
APPENDIX TABLE 2. Comparison of circulatory and respiratory supports within 24 hours after patent ductus arteriosus ligation between the patients with $\mathrm{Ea} / \mathrm{Ees} \geq 1.0$ and $<1.0$

\begin{tabular}{lcc}
\hline & $\begin{array}{c}\text { Ea/Ees } \geq \mathbf{1 . 0} \\
(\mathbf{N}=\mathbf{1 8})\end{array}$ & $\begin{array}{c}\text { Ea/Ees }<\mathbf{1 . 0} \\
(\mathbf{N}=\mathbf{1 7})\end{array}$ \\
\hline Mean doses of catecholamines $(\mathrm{N})$ & $(18)$ & $(17)$ \\
Dopamine $(\mu \mathrm{g} / \mathrm{kg} / \mathrm{min})$ & $3.40 \pm 0.82$ & $3.18 \pm 1.16$ \\
Dobutamine $(\mu \mathrm{g} / \mathrm{kg} / \mathrm{min})$ & $0.55 \pm 1.39$ & $0.00 \pm 0.00$ \\
Mechanical ventilation $(\mathrm{N})$ & $(18)$ & $(17)$ \\
FIO & $0.25 \pm 0.06$ & $0.26 \pm 0.10$ \\
SIMV $(\mathrm{N})$ & $(10)$ & $(13)$ \\
RR $(/ \mathrm{min})$ & $31.5 \pm 7.47$ & $35.5 \pm 8.15$ \\
PIP $(\mathrm{mm} \mathrm{Hg})$ & $19.3 \pm 4.19$ & $18.5 \pm 4.60$ \\
PEEP $(\mathrm{mm} \mathrm{Hg})$ & $4.91 \pm 0.31$ & $4.91 \pm 0.51$ \\
$\mathrm{HFO}(\mathrm{N})$ & $(8)$ & $(4)$ \\
$\quad \mathrm{MAP}(\mathrm{mm} \mathrm{Hg})$ & $10.1 \pm 0.75$ & $10.4 \pm 1.67$ \\
SV $(\mathrm{mL})$ & $10.5 \pm 1.04$ & $9.40 \pm 0.54$ \\
$\mathrm{Blood}$ gas data & & \\
pH & $7.38 \pm 0.07$ & $7.34 \pm 0.01$ \\
$\mathrm{BE}$ & $2.69 \pm 3.72$ & $0.08 \pm 4.29$ \\
Lactate $(\mathrm{mmol} / \mathrm{L})$ & $1.85 \pm 1.07$ & $1.50 \pm 0.71$ \\
\hline
\end{tabular}

Data are presented as the mean \pm SD. Ea/Ees, Ventriculoarterial coupling, $N$, number of treated patients; Fio2, fractional inspired oxygen concentration; SIMV, synchronized intermittent mandatory ventilation; $R R$, respiratory rate; $P I P$, peak inspiratory pressure; $P E E P$, positive end-expiratory pressure; $H F O$, high-frequency oscillation; $M A P$, mean airway pressure; $S V$, stroke volume; $B E$, base excess. 